\title{
Proposal for an Experimental-Numerical Method for Friction Description in Sheet Metal Forming
}

\author{
Tomasz Trzepieciński1 - Hirpa G. Lemu2,* \\ 1 Rzeszow University of Technology, Department of Materials Forming and Processing, Poland \\ 2 University of Stavanger, Department of Mechanical and Structural Engineering and Materials Technology, Norway
}

\begin{abstract}
During the forming of draw pieces with complex shapes, such as car bodies, it is necessary to use dies with varying outline curvatures and varying radii of edge fillets. In such conditions, using the cylindrical counter-samples for friction modelling on the die fillet surface does not fully reflect the friction conditions on the edge of the die. In this article, a proposal for an experimental numerical method of friction determination on the rounded profiles of punch edges is presented. The method involves a bending under tension (BUT) test that is devised to simulate the frictional conditions over the punch radii. Numerical simulations of BUT tests were conducted with ABAQUS software. An elastic-plastic approach with Hill's (1948) anisotropic material formulation and isotropic strain hardening were considered. Results of both experimental and numerical approaches confirmed the usefulness of the proposed method.

Keywords: bending-under-tension, BUT test, finite element method, friction, friction coefficient

Highlights

- An experimental-numerical method of friction determination on the rounded profiles of forming punch edges is proposed

- A bending under tension test is devised to simulate the frictional conditions over the punch radii.

- The numerical simulations of bending under tension tests are conducted with ABAQUS software.

- The surface topographies of DDQ steel sheet at different strain states and lubrication conditions are studied.
\end{abstract}

\section{INTRODUCTION}

Frictional resistance in sheet metal forming depends on physical and chemical factors, among others, acting on the contact surface, the roughness and topography of sheet and tools, the dynamics of the loads, lubrication conditions, and the temperature [1] and [2]. Many kinds of friction tests have been developed to determine the coefficient of friction in sheet metal forming. Among the available methods, the most frequently used are the strip-drawing test, the draw bead simulator friction test and bending the under tension test.

The bending under tension (BUT) test is a group of tests in which a work piece is stretched and bent during the experiment so that the friction coefficient is measured under conditions similar to those encountered in the real forming process. The traditional way of performing BUT tests is with differential measurements in which two tests are carried out after each other, one by drawing the work piece over a fixed circular cylindrical tool-pin, the other over a freely rotating pin, with the understanding that no sliding takes place. The difference in front tension measured in two tests gives an estimate of the friction. One drawback of this method is the stochastic variations, which may cause large scatter, and the fact that steady-state conditions must be present while measuring.
Many BUT tests have contributed to the knowledge about sheet-forming tribology [3] and [4]. A new methodology to determine the friction coefficient via a BUT test, considering the pressure non-uniformity, has been suggested by Kim et al. [5]. Miguel et al. [6] used a BUT test to evaluate pressure in the die radius and the corresponding lubricated regime under multi-axial stress conditions.

Deng and Lovell [7] and Lovell and Deng [8] studied the influence of stamping process parameters and wear mechanisms on the characterization of interfacial friction in coated steel sheets. In these studies, it was determined that the lubricant properties had little influence on the final surface roughness of the deformed sheet. Considering the influence of the pin size, the results showed that the friction coefficient increased with decreasing pin radius values.

Intending to improve the chance of success before production trials of more environmentally benign tribo-systems, many researchers [9] and [10] described the equipment for realization of BUT tests and developed a methodology for off-line evaluation of tribo-systems for sheet metal forming. Furthermore, the BUT investigations conducted on the friction of galvannealed interstitial free sheet steels by Garza and Van Tyne [11] shown that the coefficient of friction also increases as the amount of iron content in the coating decreased. Alingner and Van Tyne [12] examined the change in the die profile of five 
coated die materials tested in conjunction with three automotive steel sheets. The zirconia die material exhibited the least amount, but the most significant change.

Based on the experimental results of the BUT test, Wiklund et al. [13] developed a theoretical model to predict that the effective hardness of a surface is reduced by the presence of underlying plastic flow. The results of investigations of Pereira et al. [14] provide a qualitative description of the evolution and distribution of contact pressure at the die radius for a typical channel-forming process. The proposed contact pressure behaviour for the BUT test was compared to other results available in the literature. Both experimental and numerical approaches to the BUT test carried out by the authors [15] showed that, although the sheet was drawn over a cylindrical pin, the plane strain state assumed over the entire width of the sample is affected by the behaviour of the sample during bending. The stretch-drawing type tests (i.e. BUT) are widely used to investigate the influence of several material and technological parameters [16] and [17].

In this article, we propose an experimentalnumerical method of friction determination on a punch edge with a rounded profile as a modification of the classic BUT test method.

\section{DESCRIPTION OF BUT TEST METHOD}

The BUT test is performed in two steps. First, a strip is drawn over a freely turning roller (Fig. 1), and the values of both pulling $F_{1}$ and back tension $F_{2}$ forces are determined. The difference between $F_{1 t}$ and $F_{2 t}$ forces is the force $F_{b}$ due to bending and unbending of the sample over the roller. A second strip is then drawn over a fixed roller, and the corresponding pulling $F_{1}$ and back tension forces $F_{2}$, are determined.

Assuming that there is a constant friction coefficient $\mu$ in the contact region and that the wrap angle $\gamma$ (Fig. 1) is constant during the test according to the equilibrium of all forces acting on an elemental cut of the strip $d \gamma$, it can be shown that:

$$
\begin{gathered}
F+q \mu w R d \gamma-(F+d F)=0, \\
q w R d \gamma-F \sin \frac{d \gamma}{2}-(F+d F) \sin \frac{d \gamma}{2}=0,
\end{gathered}
$$

where $q$ is the unit normal contact pressure and $w$ is the width of the strip.

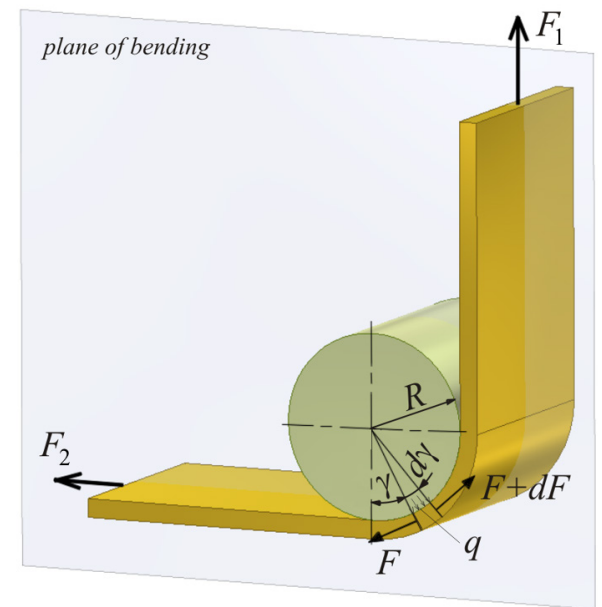

Fig. 1. Forces acting on an elemental cut of the strip

For a very small $d \gamma$ one can assume that $\sin \frac{d \gamma}{2} \approx \frac{d \gamma}{2}$ and $d F<<F$. Thus, combining Eq. (1) and Eq. (2) gives:

$$
\mu d \gamma=\frac{d F}{F} .
$$

Integrating Eq. (3) and taking into account $\gamma=\pi / 2$, the coefficient of friction is determined to be:

$$
\mu=\frac{2}{\pi} \ln \left(\frac{F_{1}}{F_{2}}\right)
$$

Formulas given by several authors take into consideration roller radius $R$ and sheet thickness $g$. For a $90^{\circ}$ bend angle, the friction coefficient $\mu$ can be determined from the formulae:

$$
\mu=\frac{2}{\pi}\left(\frac{R+g / 2}{R}\right) \ln \left(\frac{F_{1}-F_{b}}{F_{2}}\right),
$$

\section{MOTIVATIONS}

Separation of frictional resistance and bending resistance in the BUT test is only possible by using a cylindrical counter-sample. The use of non-cylindrical counter-samples does not allow carrying out the test in terms of rotational counter-sample.

Assuming the plane strain state of the sample in the theoretical analysis of friction tests is, therefore, a simplification. During the forming of draw pieces with complex shapes, such as car bodies, there are dies with varying outline curvatures $(R)$ and varying radii of edge fillets ( $r$ ) (Fig. 2). 


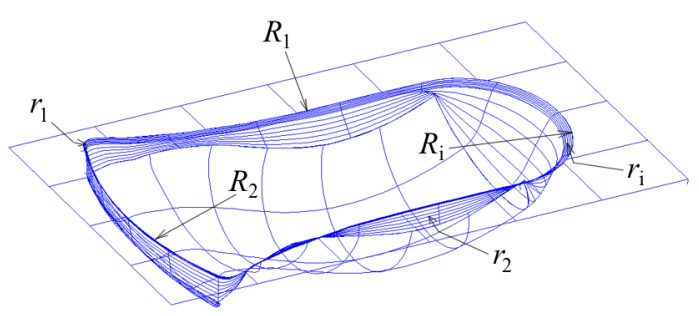

Fig. 2. Example of a die shape for sheet forming with varying outline curvature $\left(R_{i}\right)$ and varying radii of edge fillet of die $\left(r_{i}\right)$

In such conditions, using a cylindrical countersample for friction modelling on the die fillet surface does not fully reflect the friction conditions on the edge of the die, which outline changes along the perimeter of the die hole. During the standard BUT test, the flat sample is bent in the plane perpendicular to the axis of the counter-sample (Fig. 1). Analysing the simplest case of forming of the axisymmetric draw-piece, it is seen that tri-axial stress occurs state on the die edge with additional peripheral compressive stresses (Fig. 3). The tri-axial state of stress in the contact area of the sheet with the non-cylindrical counter-sample makes the nature of the changes in the surface topography of the sheet closer to reality than when using a cylindrical counter-sample. The stress state at the rounded edges of the tools, depending on the geometry of these edges, has a significant effect on the nature of the plastic deformation of sheet over the rounded die and the change of its topography.

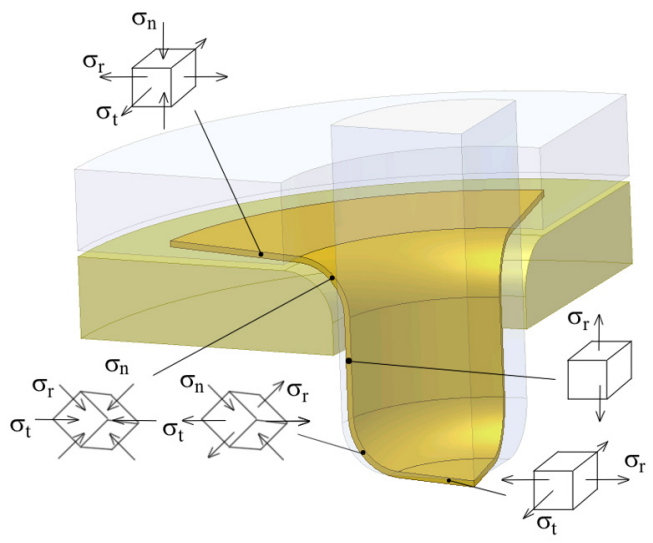

Fig. 3. Stress state during forming of axi-symmetrical draw piece; $\sigma_{r}, \sigma_{t}, \sigma_{n}$-stresses: radial, tangential and normal, respectively

\section{METHOD OF FRICTIONAL RESISTANCE DETERMINATION}

A major issue is the development of a realistic test that allows the separation of the frictional resistance and the bending resistance of the sample on rounded profiles of the die and the punch. The proposed method provides the ability to determine the coefficient of friction at the rounded edge of the tools. The formula for determining the friction coefficient is in accordance with the method for cylindrical countersamples. The shape of the proposed counter-samples makes it necessary to use a different method for determining the test forces in the condition of friction elimination via the following steps:

- experimental determination of pulling and back tension forces during the friction test using the counter-sample with the non-cylindrical profile,

- numerical determination of the pulling and back tension forces under frictionless conditions $(\mu=0)$ using the counter-sample with the noncylindrical profile.

The proposed method and counter-sample shapes for friction coefficient evaluation in the BUT test are not covered in the literature. Assuming that, during the friction test, the sample is bent at an angle of $90^{\circ}$, the coefficient of the friction is determined by modification of Eq. (5) as:

$$
\mu=\frac{2}{\pi}\left(\frac{R+g / 2}{R}\right) \ln \left(\frac{F_{\text {lexp }}-\left(F_{1 \text { num }}-F_{2 \text { num }}\right)}{F_{2 \exp }}\right),
$$

where $R$ is the radius of countersample rounding, $g$ the sheet thickness, $F_{1 \exp }$ the experimentally determined pulling force, $F_{1 \text { num }}$ the numerically determined pulling force, $F_{2 \exp }$ the experimentally determined back tension force, $F_{2 \text { num }}$ the numerically determined back tension force.

During the experiment, the sheet metal is drawn on the stationary counter-sample with the convex (Fig. 4a) or the concave (Fig. 4b) profile.
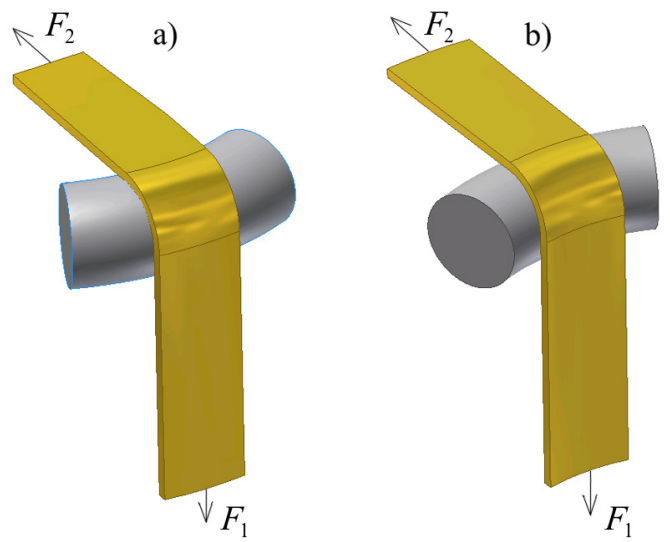

Fig. 4. Proposed methods of determination of friction coefficient on die edge with a) convex and b) concave profile 
The greater the curvature of the tool edge, the more the strain state occurring in the contact area deviates from the plane strain state occurring in a classic BUT test. The value of the bending force increases nonlinearly with increasing degree of deformation of the sheet resulting from the strainhardening phenomenon. To separate the frictional and bending resistances, the pulling force must be determined in conditions that eliminate the friction between the sheet and the counter-sample.

\section{NUMERICAL SIMULATION OF THE PROPOSED APPROACH}

The shape of the die and the punch profile determines the occurrence of the specific distribution and the value of strains in the sample, and the distribution of contact shear stress. To compare the mentioned parameters, the numerical simulations for the three profiles of counter-samples (cylindrical, convex and concave) were carried out. The radius of the die edge rounding was $7.5 \mathrm{~mm}$, and the radius of the curvature for counter-samples with concave and convex contours was $40 \mathrm{~mm}$. The material is assumed to be deep drawing quality (DDQ) steel sheet with a thickness of $1.5 \mathrm{~mm}$. The width and the length of the sample were $85 \mathrm{~mm}$ and $11 \mathrm{~mm}$, respectively. The sample was modelled with eight-node reduced integration, general-purpose linear brick elements, called C3D8R in ABAQUS terminology. Kim et al. [18] and Ramezani et al. [19] successfully used these types of elements to study the contact pressure distribution in BUT test.
An elasto-plastic material model approach has been implemented. The plastic behaviour of the metal is described by the von Mises yield criterion. Further, an isotropic strain hardening described by Hollomon's law with $C$ and $n$ parameter values according to the values in Table 1 are assumed. The rest of mechanical parameter values are assumed as follows:

- Young's modulus $E=210000 \mathrm{MPa}$,

- Poisson's ratio $v=0.3$,

- density $\rho=7860 \mathrm{~kg} \cdot \mathrm{m}^{-3}$.

To analyse the influence of different countersample profiles on the strain and pressure distribution, the contact phenomena in all cases are considered the same. The friction properties are described by Coulomb's law of friction coefficient whose value is equal to 0.2. One end of the sheet is restrained, while a displacement equal to $4 \mathrm{~mm}$ is applied to the second end.

The strain distribution for the third analysed counter-sample profiles, corresponding to this displacement, is shown in Fig. 5. The counter-sample profile determines the distribution and values of equivalent plastic strain of the sheet; for the concave profile (Fig. 5b) the maximum pressure is greater, whereas for the convex profile (Fig. 5c) it is less than the maximum plastic strain obtained for the cylindrical profile (Fig. 5a).

As depicted in Fig. 6, in the cross section of the bend sample a neutral layer exists on which the sign of the longitudinal strains is changed.

In the middle part of the sample width on the internal side, there are longitudinal compressive

Table 1. The mechanical properties of DDQ steel sheet [20]

\begin{tabular}{ccccc}
\hline $\begin{array}{c}\text { Sample } \\
\text { orientation }\end{array}$ & $\begin{array}{c}\text { Yield stress } \\
R_{e}[\mathrm{MPa}]\end{array}$ & $\begin{array}{c}\text { Ultimate tensile strength } \\
R_{m}[\mathrm{MPa}]\end{array}$ & $\begin{array}{c}\text { Hardening coefficient } \\
C[\mathrm{MPa}]\end{array}$ & $\begin{array}{c}\text { Hardening exponent } \\
n\end{array}$ \\
\hline $0^{\circ}$ & 162 & 310 & 554 & 0.21 \\
\hline $45^{\circ}$ & 163 & 322 & 542 & 0.20 \\
\hline $90^{\circ}$ & 168 & 312 & 530 & 1.27 \\
\hline average value & 164.3 & 314.7 & 542 & 1.67 \\
\hline
\end{tabular}

a)

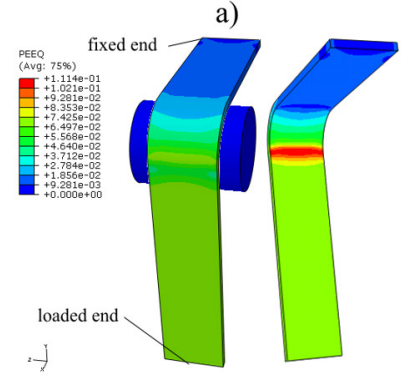

b)

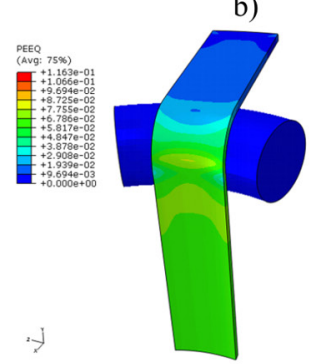

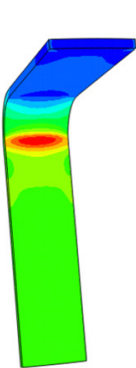

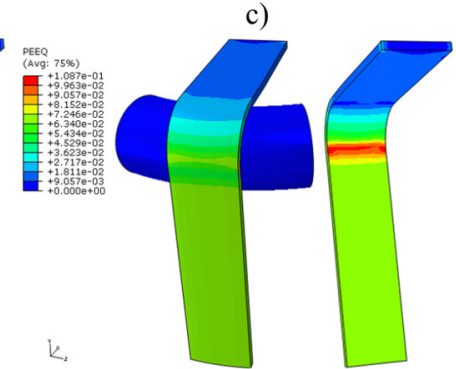

Fig. 5. Distribution of equivalent plastic strain after sheet elongation of $4 \mathrm{~mm}$ for edges of a) cylindrical, b) concave and c) convex profile 
stresses, and the strain increment is negative; on the external side, the longitudinal stresses are negative, and the strain growth is negative.

At the sample edge, the aforementioned stress and strain state is disturbed (Fig. 6) by increasing the longitudinal dimensions of the tensional layers and reducing the corresponding dimensions of the compressed layers of the sample. The use of cylindrical counter-samples in the BUT test disturbs the initial rectangular cross-section of the sample, and the middle part of the sample width is also curved.

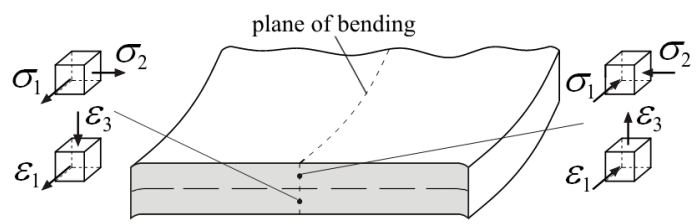

Fig. 6. Stress and strain state during bending of sheet strip, $\sigma$-stress, $\varepsilon$ - strain

After the elongation of the sample by $2 \mathrm{~mm}$, the distribution of contact pressure at surface nodes (Fig. 7) is not uniform across the width of the sheet, even when using a cylindrical counter-sample (Fig. 8). The large ratio of the width to the thickness of the sample (20/1) determines the occurrence of a specific stress and strain state on the sample thickness.

There is a significant difference in the value of the maximum pressure for the analysed profiles, from about $146 \mathrm{MPa}$ for cylindrical counter-sample (Fig. 7a) to about $178 \mathrm{MPa}$ for counter-sample with concave profile (Fig. 7c).

Such a large difference in the pressure between these profiles confirms the hypothesis of the existence of different conditions of friction and necessitates using the proposed method for determining the coefficient. After the samples were stretched to 4 $\mathrm{mm}$, the difference between the maximum values of pressure for all counter-samples varied between 8 (Figs. 7a and 8a) and $15 \mathrm{MPa}$ (Figs. 7c and 8c). It is also noted that there is a clear difference in the location of maximum pressure for the convex profile (Figs. $7 \mathrm{~b}$ and $8 \mathrm{~b}$ ) and concave profile (Figs. $7 \mathrm{c}$ and $8 \mathrm{c})$. The increase of the sample strain implies that contact pressure peaks appear near the entry and exit regions of the strip (Fig. 8), which is in agreement with the results of Kim et al. [5]. Contact pressure evolution at the die radius in sheet metal forming is studied by Pereira et al. [21], who identified three distinct phases through the numerical analysis of the BUT test: bending, an intermediate stage when the region of the sheet that was deformed at the start of the die radius has not reached the side-wall, and the final stage, which exhibits steady state contact conditions at the die radius.

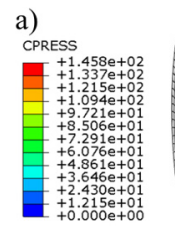

b)
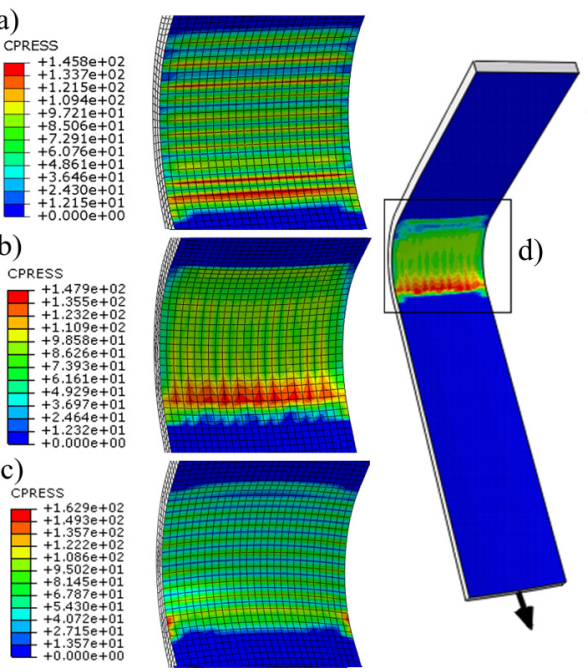

d)

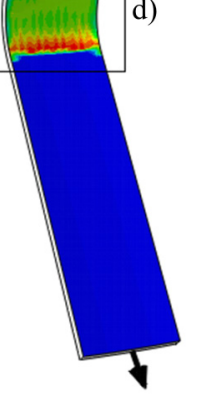

Fig. 7. Distribution of contact pressure $[\mathrm{MPa}]$ on the sheet surface after sheet elongation of $2 \mathrm{~mm}$ for edge of a) cylindrical, b) convex and c) concave profile; d) location of contact pressure measurement

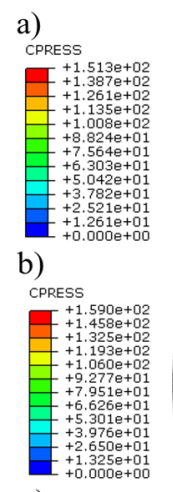

c)
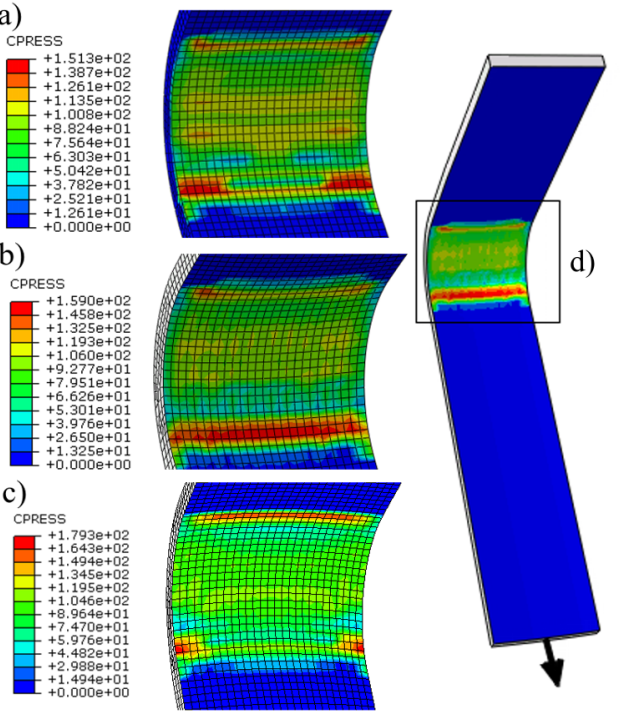

Fig. 8. Distribution of contact pressure (MPa) on the sheet surface after sheet elongation of $4 \mathrm{~mm}$ for edge of a) cylindrical, b) convex and c) concave profile; $d$ ) location of contact pressure measurement

\section{VERIFICATION OF METHOD}

\subsection{Experimental Procedure}

The schematic view of the test device is shown in Fig. 11. A test strip was held at one end in a grip supported by a load cell. A specimen of $8 \mathrm{~mm}$ width 
and $1 \mathrm{~mm}$ thick (no. 3 in Fig. 9) is wrapped around a cylindrical fixed roll with diameter of $20 \mathrm{~mm}$ and loaded in a tensile testing machine ensuring contact at an angle of $90^{\circ}$. The application of the fixed pin allows setting up the rolls in four positions to utilize the full circumference of the roll. The test was carried out using the roll made of tool steel with roughness qualities $R a=0.32 \mu \mathrm{m}$ measured parallel with the roll axis.

The forces $F_{1}$ and $F_{2}$ were measured simultaneously during the test. A major advantage of this test apparatus is that strain does not have to be measured to determine the coefficient of friction. For some tests, the effect of strain on the value of the coefficient of friction may be of interest.

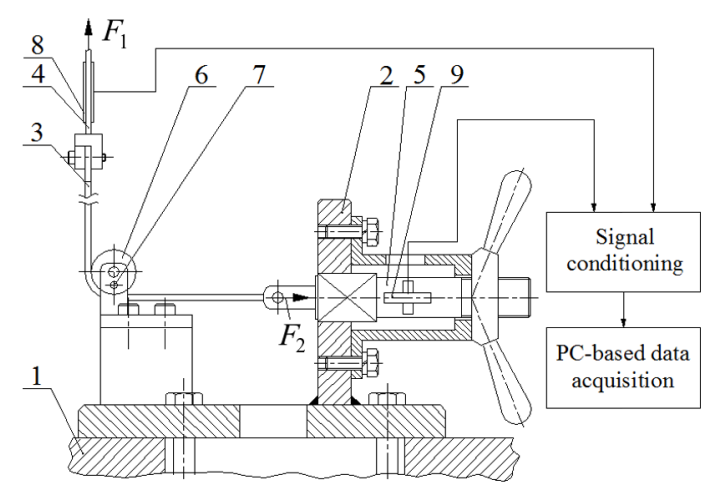

Fig. 9. Schematic view of testing device; 1 - machine base,

2 - device frame, 3 - specimen, 4 and 5 - tension members, 6 - working roll, 7 - fixing pin, 8 and 9 - strain gauges

\subsection{Numerical Modelling}

We simulated a numerically frictionless BUT test by assuming that the friction coefficient value between the sheet and the counter-sample was $\mu=0$. The sample was modelled with eight-node reduced integration C3D8R brick elements. To the best possible description of the frictionless conditions of a real BUT test, Hill's anisotropic (1948) [22] material formulation with isotropic strain hardening was implemented in the finite element (FE) model. The rest of the parameters and the mechanical property values are given in Section 4.

\section{DISCUSSION OF RESULTS}

The values of both the pulling $F_{1}$ and back tension $F_{2}$ forces increase linearly after sample yielding and then increase proportionally (Fig. 10). Furthermore, the relation between forces and the friction condition does not change for a sheet's true strain above about
0.15 . In the case of small contact pressures (true strain below 0.15), the friction coefficient increases with a true strain, which is in agreement with results of Ramezani et al. [19]. Friction coefficient of materials with little hardening capacity quickly increases at relatively small pressure. An additional comparison of pulling and back tension forces determined for different roughness qualities $R a(0.32 \mu \mathrm{m}, 0.63 \mu \mathrm{m}$ and $2.5 \mu \mathrm{m}$ ) and friction conditions (dry - dry friction, oil - lubrication conditions) shows that the $F_{1} / F_{2}$ ratio depends on pin roughness and friction conditions. The blue line in Fig. 11 represents when both forces are equal, i.e. $F_{1}=F_{2}$. The $F_{1} / F_{2}$ ratio value increases faster for higher values of pulling force.

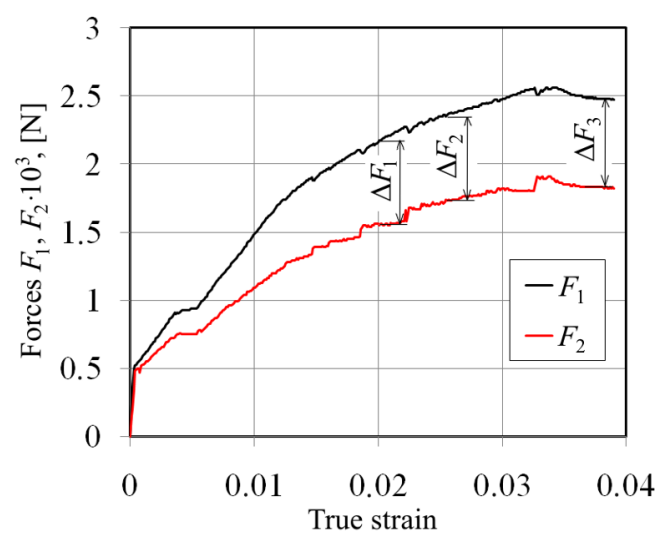

Fig. 10. Values of forces during friction tests conducted in fixed roller conditions

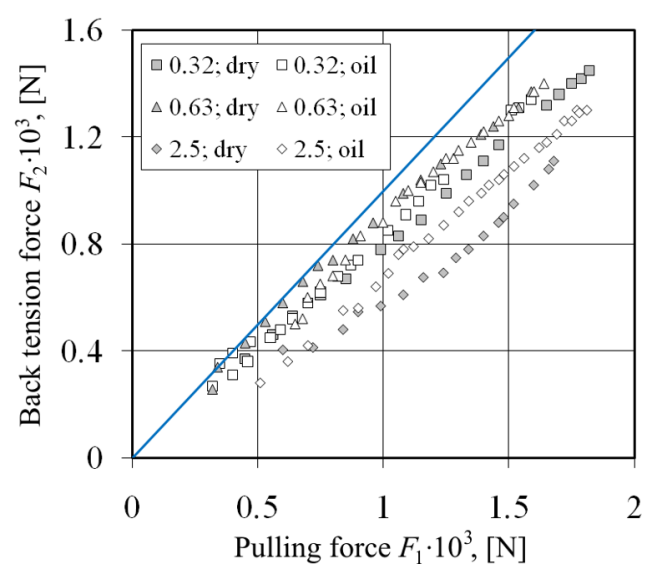

Fig. 11. Comparison of pulling $F_{1}$ and back tension $F_{2}$ forces determined for different roughness qualities $\operatorname{Ra}(0.32,0.63$ and $2.5 \mu \mathrm{m})$ and friction conditions (dry - dry friction, oil - lubrication conditions)

For bending force value evaluated as the difference between pulling and back tension force values in the case of a freely rotating pin, similar characteristics are observed (Fig. 12). The freely 
rotating pin did not eliminate the friction between the counter-sample and its fastening, so the bending force value varied during the test. In the case of an FE model, there are small variations of bending force in the whole range of values of sample true strains, because it is possible to eliminate the friction in the test in the numerical model. This is one advantage of the numerical evaluation of bending force in a BUT test.

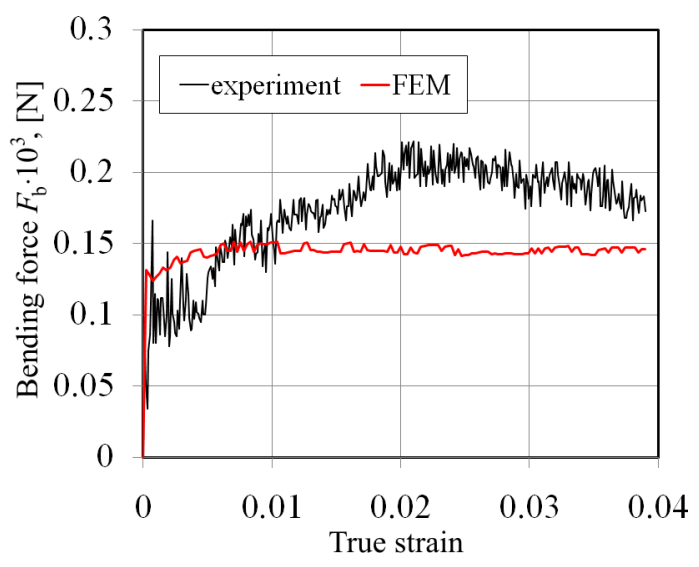

Fig. 12. Comparison of variation of bending force value determined experimentally and numerically

The increasing of sample strain allows an intensification of flattening of surface peaks. The scratches parallel to the sliding direction allow the identification of abrasion by grooving as the main contact mechanism. Simultaneously, it leads to a reduction of the volume of the valleys in the surface topography, which are mainly working as oilreservoirs (Fig. 13).

The effectiveness of the supply of lubrication at the contact zones described by the WC index is studied by Wihlborg and Crafoord [3]. The increasing of real contact area is related to peaks flattening and the change of the surface topography because of sample stretching. Furthermore, during the deformation of the sheet metal over a tool, contact occurs only at the peak asperities of both surfaces, as concluded by Figueiredo et al. [23]. The frictional response in a BUT test under mixed lubricated condition was measured by Wiklund et al. [24], who found the larger the number of oil pockets, the lower the friction. The lubricant is squeezed out on the contact spots and thus the friction is decreased. The contact conditions of anisotropical surfaces are probably not highly dependent on the sliding direction, but the increasing of active oil pockets (Fig. 13) can considerably decrease the friction. Podgornik et al. [25] and [26] investigated and compared different surface modification techniques in terms of galling properties when applied to forming tools. They concluded that the galling tendency can be greatly reduced by proper polishing of the tool surface. Based on the results of friction tests in different friction conditions, Sedlaček et al. [27] have also found the most important surface roughness parameters describing work-piece topography.

Based on the process forces of the experimental BUT test realized in fixed roller conditions and bending forces determined by experiment and numerical method, the friction coefficient value (Fig. 14) was determined by using Eq. (6). For small values of the sample true strain, a transient region of variation of the friction coefficient value is observed, because the used strain gauges can produce inaccurate forces values in the case of small measured values of forces.

In the range of the true strain of 0.01 to 0.04 , the average friction coefficient value determined experimentally equals about 0.15 . The test forces in this range increase continuously but the difference between them $\Delta \mathrm{F}$ is quite similar $\Delta F_{1} \sim \Delta F_{2} \sim \Delta F_{3}$ (Fig. 12). This relation is in excellent agreement with the

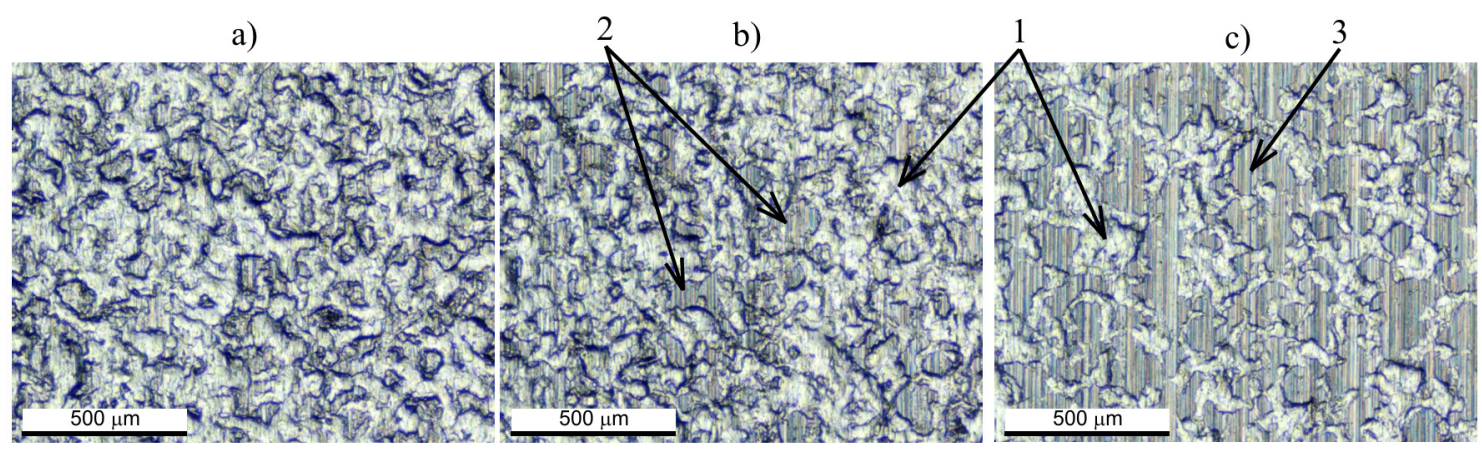

Fig. 13. Surface topography of $D D Q$ steel sheet: a) original, b) after sheet true strain 0.15 and c) after sheet true strain 0.3; oil lubrication conditions: 1 - oil pockets, 2, 3 - scratches 
results of Fratini et al. [28], who studied the influence of different lubricants on the reduction of friction in the BUT test. The main impact on the value of the friction coefficient for the analysed counter-sample shape has the values of pulling and back tension forces determined in case of the fixed pin. To take into consideration in Eq. (6) the numerically evaluated bending force $\mathrm{F}_{\text {bnum }}=F_{1 \text { nит }}-\mathrm{F}_{2 \text { num }}$ allows preserving the trend of changes of the friction coefficient value (region A in Fig. 14).

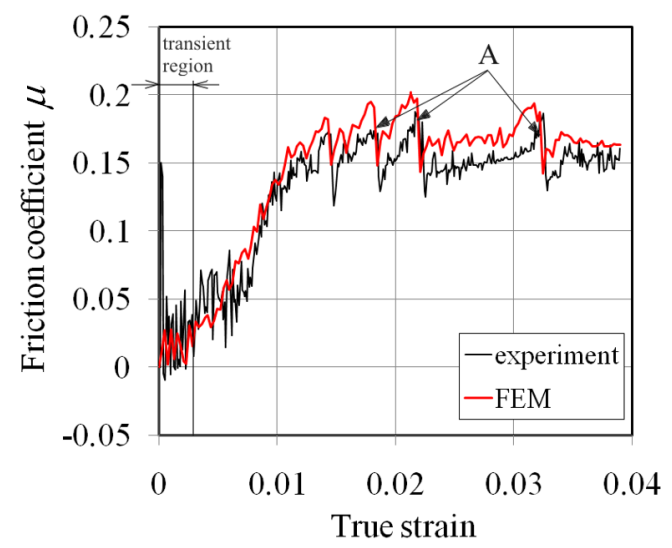

Fig. 14. Variation of friction coefficient value determined experimentally and numerically

\section{SUMMARY}

The proposed concept in this article allows the determination of friction coefficient in the case of dies with varying outline curvatures and varying radii of edge fillets. The state of stress at the rounded edges of the die and punch is determined by the geometry of these edges and has a significant impact on the plastic deformation nature of the sheet and consequently changes its topography.

The counter-sample profile determines the distribution and values of equivalent plastic strain of the sheet: for the concave profile the maximum pressure is greater, whereas for the convex profile there is less maximum plastic strain obtained for the cylindrical profile. Different friction conditions of all analysed profiles are also determined by the distribution and value of contact pressure. The difference in the value of maximum contact pressure depends on the sample elongation and varies between $10 \mathrm{MPa}$ and $30 \mathrm{MPa}$ for all analysed die rounded profiles.

The values of pulling and back tension forces determined in the case of the fixed pin have the main impact on the value of friction coefficient for the analysed counter-sample shape. The bending force value has a smaller effect on the accuracy of friction coefficient value determination in the BUT test. The experimental investigations and numerical approach confirmed that the proposed experimental-numerical method can be useful for the determination of the friction coefficient in the rounded profile of dies.

\section{REFERENCES}

[1] Volk, M., Nardin, B., Dolšak, B. (2011). Application of numerical simulations in deep-drawing process and holding system with segments' inserts. Strojniški vestnik - Journal of Mechanical Engineering, vol. 57, no. 9, p. 697-703, Dol:10.5545/svjme.2010.258.

[2] Stachowicz, F., Trzepieciński, T., Pieja, T. (2010). Warm forming of stainless steel sheets. Archives of Civil and Mechanical Engineering, vol. 10, no. 4, p. 85-94, D0l:10.1016/S16449665(12)60034-X.

[3] Wihlborg, A, Crafoord, R. (2001). Steel sheet surface topography and its influence on friction in a bending under tension friction test. International Journal of Machine Tools and Manufacture, vol. 41, no. 13-14, p. 1953-1959, DOI:10.1016/S0890-6955(01)00060-8.

[4] Hilditch, T.B., Speer, J.G., Matlock, D.K. (2007). Influence of low-strain deformation characteristics of high strength sheet steel on curl and springback in bend-under-tension tests. Journal of Material Processing Technology, vol. 182, no. 1-3, p. 84-94, DOI:10.1016/J.jmatprotec.2006.06.020.

[5] Kim, Y.S., Jain, M.K., Metzger, D.R. (2012). Determination of pressure-dependent friction coefficient from drawbend test and its application to cup drawing. International Journal of Machine Tools \& Manufacture, vol. 56, p. 69-78, D0I:10.1016/j.jimachtools.2011.12.011.

[6] Miguel, V., Coello, J., Calatayund, A., Manjabacas, M.C., Martínez, A., Ferrer, C. (2009). An approach to evaluation of sheet bending force under successive multiaxial stress condition. Journal of Materials Processing Technology, vol. 209, no. 3, p. 1588-1596, D0l:10.1016/j. jmatprotec.2008.04.016.

[7] Deng, Z., Lovell, M.R. (2000). Effects of lubrication and die radius on the friction behavior of $\mathrm{Pb}$-coated sheet steels. Wear, vol. 244, no. 1-2, p. 41-51, D0l:10.1016/S00431648(00)00430-0.

[8] Lovell, M.R. Deng, Z. (2002). Characterization of interfacial friction in coated sheet steels: influence of stamping process parameters and wear mechanisms. Tribology International, vol. 35, no. 2, p. 85-95, D0l:10.1016/S0301-679X(01)00097-4.

[9] Andreasen, J.L., Olsson, D.D., Chodnikiewicz, K., Bay, N. (2006). Bending under tension test with direct friction measurement. IMechE Part B Journal of Engineering Manufacture, vol. 220, no. 1, p. 73-80, DOI:10.1243/095440505X32913.

[10] Ceron, E., Bay, N. (2013). A methodology for off-line evaluation of new environmentally friendly tribo-systems for sheet metal forming. CIRP Annals - Manufacturing Technology, vol. 62, no. 1, p. 231-234, D0I:10.1016/j.cirp.2013.03.062.

[11] Garza, L.G., Van Tyne, C.J. (2007). Friction and formability of galvannealed interstitial free sheet steels. Journal of 
Materials Processing Technology, vol. 187-188, p. 164-168, DOl:10.1016/J.jmatprotec.2006.11.062.

[12] Alinger, M.J., Van Tyne, C.J. (2003). Evolution of die surfaces during repeated stretch-bend sheet steel deformation. Journals of Materials Processing Technology, vol. 141, no. 3, p. 411-419, D0I:10.1016/S0924-0136(03)00390-X.

[13] Wiklund, D., Rosén, B.-G., Wihlborg, A. (2009). A friction model evaluated with results from a bending-under-tension test. Tribology International, vol. 42, no. 10, p. 1448-1452, DOI:10.1016/j.triboint.2009.05.008.

[14] Pereira, M.P., Duncan J.L., Yan W., Rolfe B.F. (2009). Contact pressure evolution at the die radius in sheet metal stamping. Journal of Materials Processing Technology, vol. 209, no. 7, p. 3532-3541, D0I:10.1016/j.jmatprotec.2008.08.010.

[15] Lemu, H.G., Trzepieciński, T. (2013). Numerical and experimental study of frictional behavior in bending under tension test. Strojniški vestnik - Journal of Mechanical Engineering, vol. 59, no. 1, p. 41-49, D0l:10.5545/svjme.2012.383.

[16] Figueiredo, L., Ramalho, A., Oliveira, M.C., Menezes, L.F. (2011). Experimental study of friction in sheet metal forming. Wear, vol. 271, no. 9-10, p. 1651-1657, D0l:10.1016/j. wear.2011.02.020.

[17] Hadoush, A., van den Boogaard, A.H., Emmens, W.C. (2011). A numerical investigation of the continuous bending under tension test. Journal of Materials Processing Technology, vol. 211, no. 12, p. 1948-1956, D0l:10.1016/j. jmatprotec.2011.06.013.

[18] Kim, Y.S., Jain, M.K., Metzger, D.R. (2004). A finite element study of capstan friction test. AIP Conference Proceedings, vol. 712, p. 2264-2269, Dol:10.1063/1.1766872.

[19] Ramezani, M., Neitzert, T., Pasang, T., Sellès, M.A. (2014). Characterization of friction behaviour of AZ80 and ZE10 magnesium alloys under lubricated contact condition by strip draw and bend test. International Journal of Machine Tools \& Manufacture, vol. 85, p. 70-78, D0l:10.1016/j. ijmachtools.2014.05.006.
[20] Trzepieciński, T. (2010). 3D elasto-plastic FEM analysis of the sheet drawing of anisotropic steel sheet metals. Archives of Civil and Mechanical Engineering, vol. 10, no. 4, p. 95-106, DOI:10.1016/S1644-9665(12)60035-1.

[21] Pereira, M.P., Yan, W., Rolfe, B.F. (2008). Contact pressure evolution and its relation to wear in sheet metal forming. Wear, vol. 265, no. 11-12, p. 1687-1699, Dol:10.1016/j. wear.2008.04.042.

[22] Hill, R. (1948). A theory of the yielding and plastic flow of anisotropic metals. Proceedings of the Royal Society of London, vol. 193, p. 281-297, D0I:10.1098/rspa.1948.004.

[23] Figueiredo, L., Ramalho, A., Oliveira, M.C, Menezes, L.F. (2011). Experimental study of friction in sheet metal forming. Wear, vol. 271, no. 9-10, p. 1651-1657, Dol:10.1016/j. wear.2011.02.020.

[24] Wiklund, D., Rosén, B.-G., Gunnarsson, L. (2008). Frictional mechanisms in mixed lubricated regime in steel sheet metal forming. Wear, vol. 264, no. 5-6, p. 474-479, D0l:10.1016/j. wear.2006.08.032.

[25] Podgornik, B., Hogmark, S. (2006). Surface modification to improve friction and galling properties of forming tools. Journal of Materials Processing Technology, vol. 174, no. 1-3, p. 334341, D0I:10.1016/j.jmatprotec.2006.01.016.

[26] Podgornik, B., Hogmark, S., Sandberg, O. (2006). Proper coating selection for improved galling performance of forming tool steel. Wear, vol. 261, no. 1, p. 15-21, D0l:10.1016/j. wear.2005.09.005.

[27] Sedlaček, M., Vilhena, L.M.S., Podgornik, B., Vižintin, J. (2011). Surface topography modelling for reduced friction. Strojniški vestnik - Journal of Mechanical Engineering, vol. 57, no. 9, p. 674-680, DOI:10.5545/sv-jme.2010.140.

[28] Fratini, L., Lo Casto, S., Lo Valvo, E. (2006), A technical note on an experimental device to measure friction coefficient in sheet metal forming. Journal of Materials processing Technology, vol. 172, no. 1, p. 16-21, D0I:10.1016/j.matprotec.2005.08.008. 